\title{
Gas-Dynamic Modeling of Gas Turbine Engine Components Collaborative Workflow
}

\author{
A.V. Krivcov ${ }^{*}$, L.S. Shabliy and O.V. Baturin
}

Samara State Aerospace University (SSAU), 443086, Russia

\begin{abstract}
The aim of this article was the development of the gas-dynamic models allowing to calculate the working processes of the gas turbine engine (GTE) in the compressor, in the combustion chamber and in the turbine at the same time. The possibilities of software systems for complex engine workflow modeling are specified. The advantages and disadvantages of the presented methods are specified. The results of complex GTE simulation in a single software product are presented. It is shown that the results of a complex gas dynamic modeling are in a good agreement with the calculation results obtained using a calibrated one-dimensional thermodynamic model.
\end{abstract}

Keywords: Boundary conditions, complex operation of units, computational fluid dynamics, computational mesh, gas turbine engine, numerical modeling, turbulence models.

\section{ARTICLE IMPORTANCE}

Thanks to the development of theoretical ideas about the workflow and the capabilities of computer technologies the units of modern gas turbine engines (GTE) have achieved a high degree of perfection. In this regard, the further improvements with a view to an evident reduction in fuel consumption becomes harder and harder. The only source of GTE elements performance increase is the mutual consideration of their impact on each other, as many researchers noted that the characteristics of an isolated unit and the unit operating as the part of an engine may vary significantly.

Traditionally, each of the engine units is projected by separate departments of an engine-building company according to its own techniques. At that the estimate of the units mutual influence and the coordination of their operation is performed only to rough calculation procedures or during the finished product testing. This method is a long, expensive and complicated one, as it does not allow to take into account completely the mutual influence of neighboring units during the design phase, reducing the development quality and increasing the costs for the revealed problems solution.

The progress of Computational Fluid Dynamics (CFD) methods and the power of computers allowed to replace the considerable part of the testing with fast and cheap calculations, allowing to predict the flow behavior of the individual GTE units with a reasonable accuracy. CFDmodeling of GTE units workflow considering the mutual influence of units allows to obtain more reliable pictures of the gas-dynamic channel parameters distribution. Besides, it will allow to assess the impact of different modes, external and internal factors on the gas turbine engines performance and the laws of its collaboration, as well as to simulate the engine parameters change at the change of its operation conditions.

The literature analysis shows that the problem of the engine collaborative workflow modeling is explored by several different research groups in different countries [1-4], but neither of them have not brought them to the state suitable for a wide practical application because of various reasons.

\section{METHODS OF COLLABORATIVE GTE WORKFLOW MODELING}

As is well known, the GTE operating in a steady state must satisfy the following conditions: the constant flow rate of a working fluid in the engine elements, the equality of turbine and compressor power and the same speed of rotor rotation conditioned by kinematic coupling $[5,6]$. For this reason, the following main regularities shall be observed during the CFD modeling of the gas generator workflow:

- mass flow of the working fluid at the boundaries of adjacent calculated zones should be identical;

- $\quad$ the value of the flow mass median total enthalpy at the boundaries of the adjacent calculated zones should be kept constant;

- $\quad$ the pressure, temperature and velocity values, as well as their distribution on the boundaries of calculated zones should be identical;

- $\quad$ compressor rotor and turbine rotation speed must be the same;

- $\quad$ the rotor powers (torque moments) of the turbine and compressor models must be the same for all set conditions.

The authors have formulated two approaches of CFD workflow modeling in GTE [4], for the performance of the following requirements: 
the use of several specialized programs, each of which is the most appropriate to describe the workflow of a specific unit;

- in one universal program allowing perform simultaneous modeling of the processes at once in all gas generator units.

The first approach allows us to calculate the operational process of each unit in the program most appropriate for this purpose with the optimal model and solution program settings, as well as to attract the most appropriate physical models. This provides a more qualified process modeling and requires less computing resources, as GTE elements are calculated individually. The disadvantage of this approach is revealed by the need of data exchange between different programs, with the conversion of description formats for the input/output data and the work fluid operational body properties. Another drawback is the one-sided effect of the previous element parameters on the unit located downstream. At that, the complete engine workflow modeling in different programs requires the development of an iterative calculations series with the multiple specifications of boundary conditions [4].

The second approach does not have such deficiencies. The universal CFD program develops a computational model consisting of several GTE zone units, and the data exchange between them is easily established by the standard program tools. This approach may be easily implemented in practice, but it has some significant drawbacks. First of all, in this case, the model settings are "universal" ones that is not optimal for each unit. Secondly, the averaging of parameters during the transfer from one area to another, located downstream, is an additional source of errors, which are accumulated as the working body moves along the computational domain. Thirdly, by using such an approach in all components carried the calculation of all possible components for working bodies is performed. These components may be present in the stream, which significantly increases the number of solved equations and the calculation time.

One of the main problems of engine modeling is that the CFD programs do not provide with the standard means for automatic power balance (of torques) supply on the GTE rotor. For this reason, it is necessary to attempt for the compressor and the turbine equal capacity achievement by adjusting the fuel flow or the rotor rotation frequency during the calculation automatically, manually or using a macros subprogram implementing the control algorithm. The regulation method selection is defined by the control system operational algorithm implemented into the engine: the constant fuel consumption at measurable rotation frequency or at constant rotation frequency for fuel consumption correction [7].

\subsection{Modeled Engine Basic Data}

The data of single-shaft engine designed at the faculty of aircraft engines SSAU (see Fig. 1) were used during the study. This engine has the following specific parameters [8]:

- $\quad$ compressor pressure ratio $\operatorname{Pr}=4.5$;

- $\quad$ max gas temperature, $\mathrm{Tg} *=1100 \mathrm{~K}$;

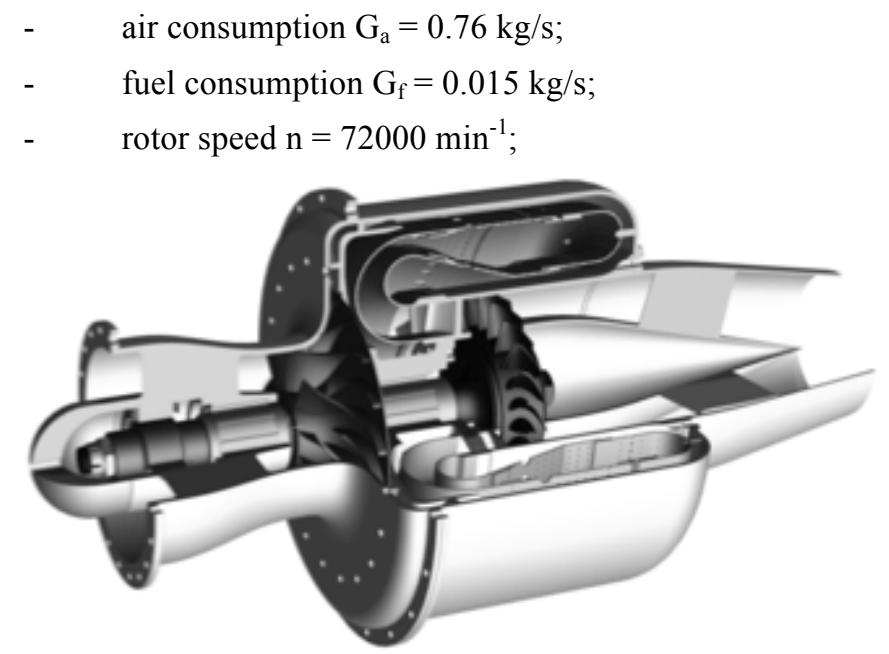

Fig. (1). Explored GTE appearance.

\subsection{Calculation Model Description}

The engine workflow modeling was performed by a universal software package ANSYS CFX. The computational model (Fig. 2) consisted of preliminary prepared grid models of an intake input device, a centrifugal compressor impeller, a vane diffuser, a combustion chamber, a nozzle unit, an axial turbine impeller, as well as a nozzle. The models of all turbomachine elements considered the presence of radial clearances and contained one interscapular channel with periodical boundary conditions on the side walls. The model does not take into account the presence of leaks and the working body samples. The heat exchange between the stream and the walls of the air-gas channel is not taken into account.

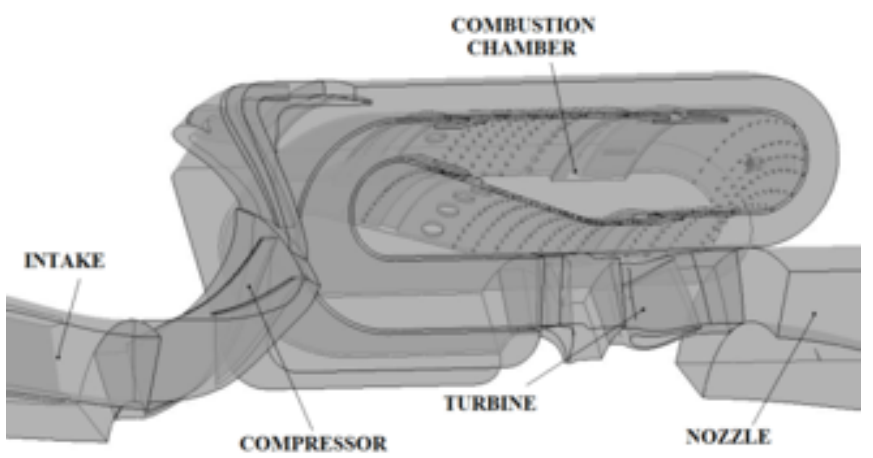

Fig. (2). Computational model appearance of the explored GTE working process.

The grid model of the combustion chamber is a $45^{\circ}$ sector with the periodic boundary conditions on the lateral boundaries. The computational models of the intake input device and the nozzle are made as the sectors with a central angle of $90^{\circ}$. The total number of the model grid elements made $5 \mathrm{mln}$. cells. The turbomachines had a structured hexagonal calculation grid. The combustion chamber, the nozzle and the input device had the unstructured tetrahedral grid with a detailed prismatic layer. The data transfer between neighboring unit models was implemented via Stage interface which implements the homogenization of the flow parameters in the circumferential direction. 
The mixture of gaseous components was used as the working body during simulation: oxygen $\mathrm{O}_{2}$, nitrogen $\mathrm{N}_{2}$, carbon dioxide $\mathrm{CO}_{2}$, water $\mathrm{H}_{2} \mathrm{O}$ and conditional kerosene Jet A.

The combustion was modeled using the model of vortex dissipation (Eddy Dissipation), based on the assumption that the chemical reaction proceeds much faster than the transportation processes in the flow. Once the reagents are mixed at the molecular level, they instantly form a chemical reaction product. In turbulent flows, the mixing time is determined by the vortex properties and hence the reaction rate is proportional to the time of mixing, determined by the turbulent kinetic and dissipation energy. For the kerosene combustion cases the following chemical reaction equation is the basis for the combustion process calculation [9]:

Jet $\mathrm{A}+17,75 \mathrm{O}_{2}=12 \mathrm{CO}_{2}+11,5 \mathrm{H}_{2} \mathrm{O}+\mathrm{Q}$

The boundary conditions were applied in the developed unified model of the gas generator workflow:

- at the input device inlet-atmospheric pressure, the temperature, as well as orthogonal flow direction;

- $\quad$ at the nozzle output: static pressure of the undisturbed atmosphere;

- $\quad$ rotor rotation speed was set equal in magnitude and direction for the compressor and turbine;

- gaseous fuel flow rate in the combustion chamber.

$K$-epsilon model was applied as a turbulence model with scalable wall functions. The problem was solved in a stationary setting.

During the first phase the stream was obtained for the engine without the fuel burning in the combustion chamber. Then, this solution was used to initialize the calculation process by taking into account the process of burning.

During the solution process the most important parameters characterizing the GTE workflow and the calculation were visualized: the flow temperatures in the typical cross-sections, the imbalance of mass flow, the compressor and turbine capacity, on the basis of which the decisions on the solution conclusion were taken. The experience obtained during the calculation showed that the solution process by using a single computational model in ANSYS CFX program has a low resistance, especially at the calculation based on combustion. Such a low resistance makes it difficult to obtain results. For example, the temperature fluctuations in the "hot" part of the engine relative to an average value rise up to $30 \mathrm{~K}$. This fact may indicate the non-stationary nature of the explored process or the instability of the applied mathematical solution methods. For these reasons, the decision process requires a constant supervision by an engineer-estimator. During the calculation the fuel consumption was adjusted manually so that the magnitude of the compressor and turbine torques coincided with the accuracy of $5 \%$.

\subsection{Modeling Results}

Using the described above model the calculation of the considered engine throttle characteristics was performed under standard atmospheric conditions. Ten points were calculated for this characteristic at different rotation frequencies in the range of $15 \ldots 100$ thousand $\min ^{-1}$. The calculation period of one mode made 12 hours at the use of 48 cores of SSAU supercomputer "Sergei Korolev".

(a)

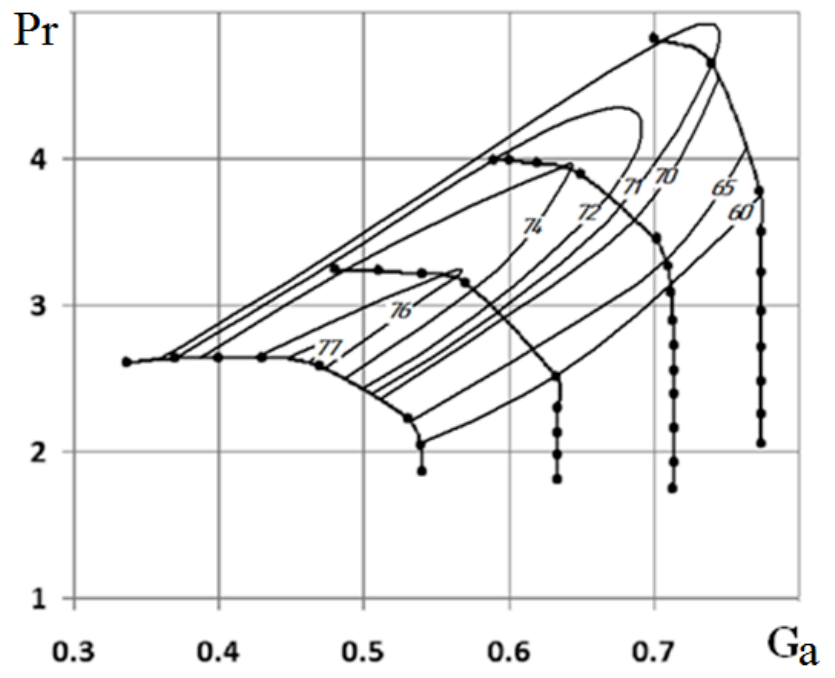

(b)

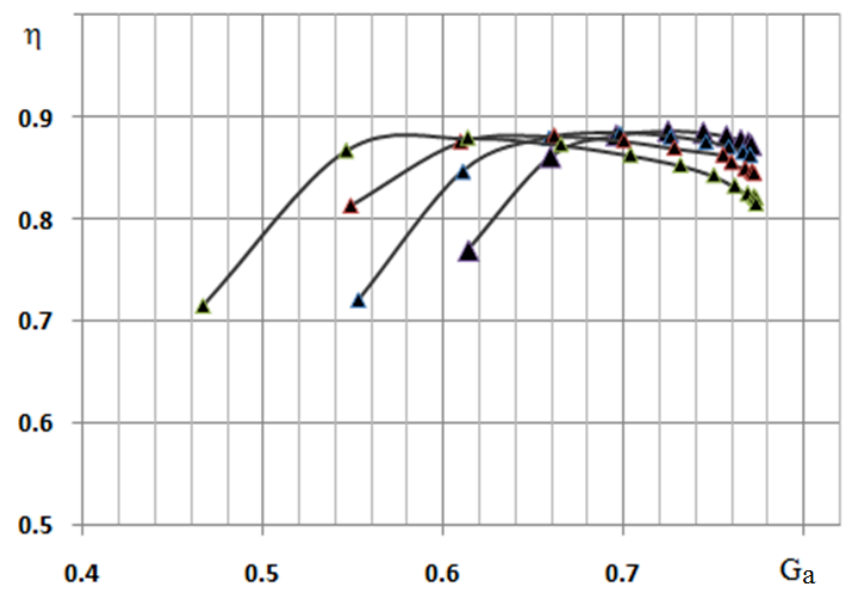

(c)

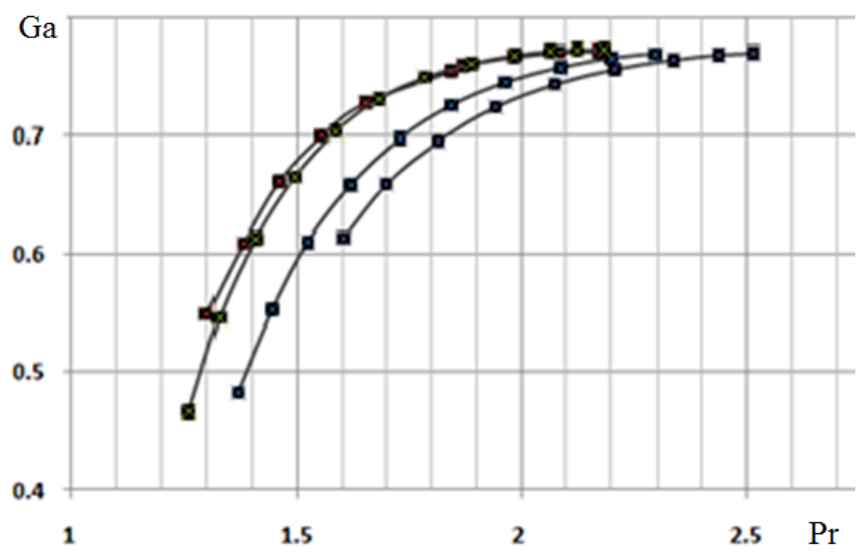

Fig. (3). Characteristics of the modeled turbine engine elements: acompressor characteristics according to given parameters, b-the turbine characteristics efficiency, c-turbine flow characteristic.

To check the adequacy of the obtained data the additional calculation was conducted in a takeoff mode using a one- 
dimensional thermodynamic model in ASTRA program [5]. This program allows you to estimate the GTE parameters on the basis of the GTE thermodynamic cycle analysis. To improve the calculations reliability the thermodynamic model were performed with the characteristics of individual engine components on the pressure, efficiency and losses obtained by the gas-dynamic modeling (see Fig. 3a-d). The thermodynamic calculation results in the ASTRA program are specified by Figs. $(\mathbf{4}, \mathbf{5})$ in as a red diamond.

Fig. (4) provides the teamwork line obtained during CFD calculation on the characteristics of the considered turbine engine compressor.

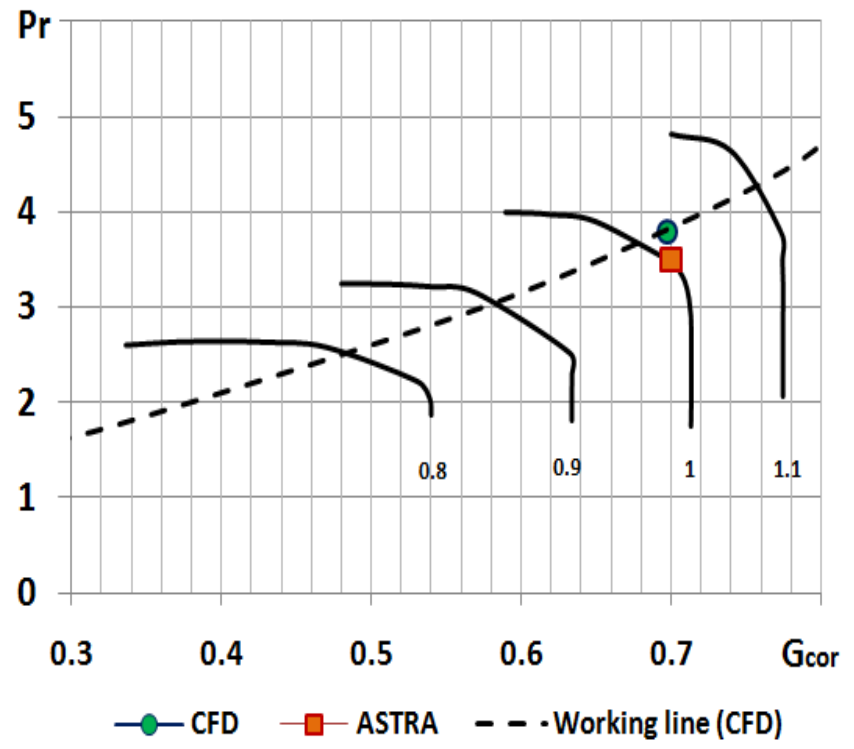

Fig. (4). The thrust $P$, the air flow through the engine $G_{\text {cor }}$ and specific fuel consumption $C_{s p}$ dependences were obtained after the calculation, as shown in Fig. (5).

The difference between the results obtained by different ways does not exceed $7 \%$. Thus, we can conclude that the CFD-calculation results do not contradict with the existing physical understanding of the GTE workflow and the model may be used to calculate its parameters and to perform modeling in various conditions. However, compared with the thermodynamic model that allows us to solve the same problems, the gas-dynamic modeling of collaborative workflow in the engine allows you to define the flow parameters at all points of the computational domain, and not only within the control sections (see Figs. 6, 7) and to consider the workflow in a more detailed way.

\section{CONCLUSION}

The conducted computational studies showed that the results obtained using the developed calculation model are in a good agreement with the thermodynamic calculations. However, during the course of work performance the significant problems were revealed. These problems are associated with long calculation periods and the need of computational resources, the instability of the solution process and a lot of the assumptions used. Besides an estimator conducting this study should be qualified and be an expert in the operation of all units, of all GTE units complex operation, of thermodynamics and the numerical simulation of gas flows and combustion processes. (a)

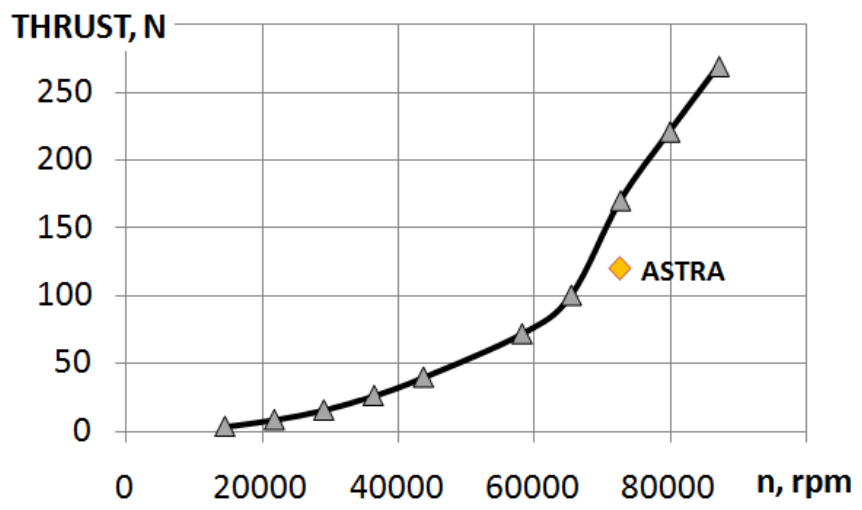

(b)
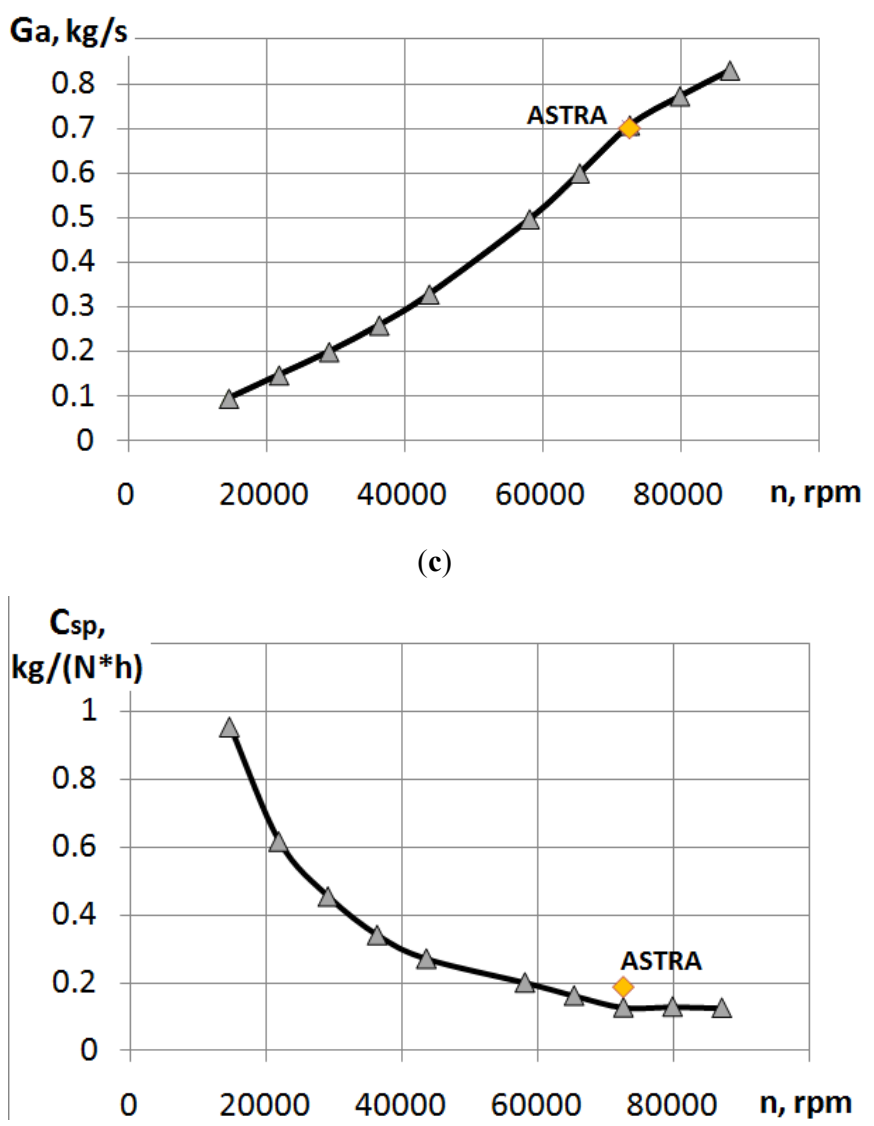

Fig. (5). Dependences on the basic parameters of the studied GTE workflow on the rotor rotation frequency: a-thrust, b-air flow, cspecific fuel consumption.

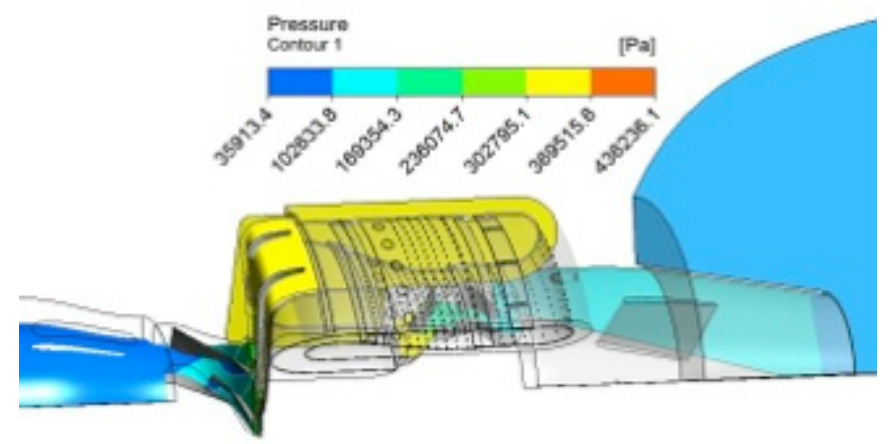

Fig. (6). Distribution of engine pressure during takeoff. 


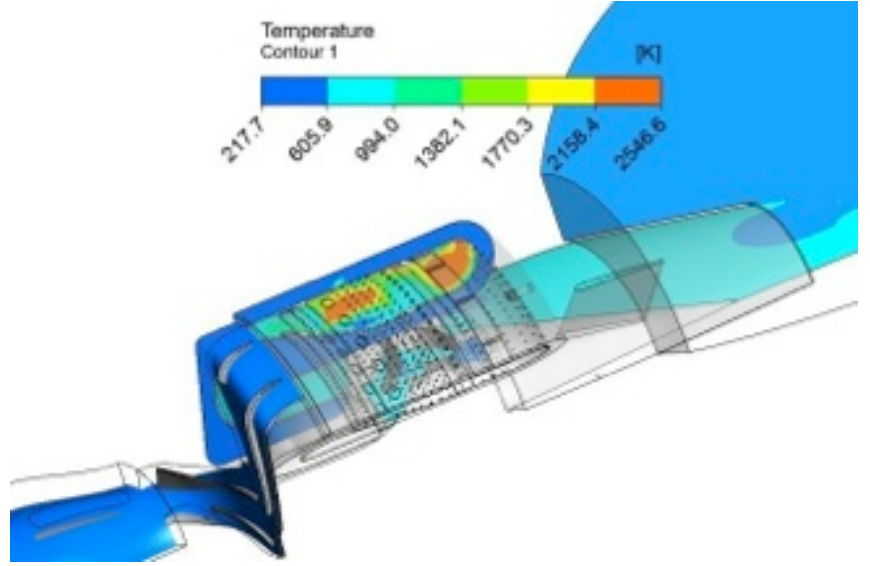

Fig. (7). Distribution of engine temperature during takeoff.

However, the gas-dynamic modeling of collaborative engine workflow has a great potential because it allows to model the mutual influence of units on each other, to explore the impact of the work conditions or geometric shapes of flow elements changes on the GTE characteristics and all the units which are included in it. For this reason, the research in this area should be continued.

\section{CONFLICT OF INTEREST}

The author confirms that this article content has no conflict of interest.

\section{ACKNOWLEDGEMENTS}

The authors thank the Associate Professor of TDLA Department Tkachenko Andrey Yurevich for the study performance support.

This work was financially supported by the Russian Federation Government (Ministry of Education) (theme code 2013-218-04-4777). This work was supported by the Ministry of education and science of the Russian Federation in the framework of the implementation of the Program of increasing the competitiveness of SSAU among the world's leading scientific and educational centers for 2013-2020 years.

\section{NOTE}

Developed by the group studying the combustion processes from NOTS GDI SSAU Department, the head of the group is Ph.D., Associate Professor Matveev S.G.
Developed by the group studying the JE workflows from TDLA SSAU Department under the leadership of Prof. Kulagin V.V.

\section{REFERENCES}

[1] W.C. Russell, S. Townsend, "A review of high fidelity, gas turbine engine simulations", //ICAS 2010, 2010. 27th International Congress of The Aeronautical Sciences.

[2] M.G. Turner, Lessons Learned from the GE90 3D Full Engine Simulations// 48th AIAA Aerospace Sciences Meeting Including the New Horizons Forum and Aerospace Exposition, AIAA 20101606.

[3] M. Turner, J.A. Reed, R. Ryder, J.P. Veres, "Multifidelity simulation of a turbofan engine with results zoomed into minimaps for a Zero-D cycle simulation", ASME GT2004-53956.

[4] A.V. Krivcov, Tehnologija modelirovanija rabochego processa gazoturbinnogo dvigatelja v SAE-sistemah [Tekst]: / A.V. Krivcov, L.S. Shablij // Vestnik Samarskogo gosudarstvennogo ajerokosmicheskogo universitet imeni akad. S.P. Koroleva (nacional'nogo issledovatel'skogo universiteta), chast' 2 -. Samara: Izdatel'stvo Samarskogo gosudarstvennogo ajerokosmicheskogo universiteta, vol. 34, 197-202, 2012.

[5] V.S. Kuz'michev, Metody i sredstva konceptual'nogo proektirovanija aviacionnyh GTD v CAE-sisteme «ASTRA» [Tekst] / V.S. Kuz'michev, A.Ju. Tkachenko, V.N. Rybakov, I.N. Krupenich, V.V. Kulagin// Vestnik Samarskogo gosudarstvennogo ajerokosmicheskogo universitet imeni akad. S.P. Koroleva (nacional'nogo issledovatel'skogo universiteta), vol. 36, pp. 169-73, 2012.

[6] V.V. Kulagin, Teorija raschet i proektirovanie aviacionnyh dvigatelej i jenergeticheskih ustanovok: Uchebnik. Osnovy teorii GTD. Rabochij process i termogazodinamicheskij analiz. Kn.1. Sovmestnaja rabota uzlov vypolnennogo dvigatelja i ego harakteristiki. Kn.2. [Tekst]/ V.V. Kulagin - M.: Mashinostroenie, 2002. -616 s.; il.

[7] V.S. Kuz'michev, V.G. Maslov, M.A. Morozov, and O.V Novikov, "Expert assessment of the scientific and engineering level of an aircraft gas turbine engine design// Izvestiya Vysshikh Uchebnykh Zavedenij. Aviatsionnaya Tekhnika (4) PP. 50-5, 1992.

[8] O.V. Baturin, Obosnovanie vybora shemy turboreaktivnogo dvigatelja dlja ispol'zovanija ego na BPLA [Tekst] / O.V. Baturin, A.Ch. Mamedov, Ju.D. Smirnova, L.S. Shablij // Mezhdunarodnyj nauchno-tehnicheskij formu, posvjashhennyj 100-letiju OAO «Kuznecov» i 70-letiju SGAU, Samara, 5-7 sentjabrja 2012 goda: Sbornik trudov v 3-h tomah. Tom 3. Vserossijskaja molodezhnaja nauchno-tehnicheskaja konferencija «Kosmos-2012». - Samara: Izdatel'stvo Samarskogo gosudarstvennogo ajerokosmicheskogo universiteta, pp. 45-47, 2012.

[9] A.V. Ivliev, Y.A. Knysh, and V.P. Lukachev, "Influence of combustion chamber geometry on toxic compound emissions", Sov. Aeronaut., vol. 20, pp. 44 -48, 1977. 